\title{
Physical and Leisure Activity in Older Community-Dwelling Canadians Who Use Wheelchairs: A Population Study
}

\author{
Krista L. Best ${ }^{1}$ and William C. Miller ${ }^{1,2}$ \\ ${ }^{1}$ Rehabilitation Sciences Graduate Program, University of British Columbia, T325-2211 Wesbrook Mall, Vancouver, Canada V6T 2B5 \\ ${ }^{2}$ GF Strong Rehabilitation Centre, 4255 Laurel Street, Vancouver, Canada V5Z 2G9 \\ Correspondence should be addressed to William C. Miller, bcmiller@telus.net
}

Received 2 September 2010; Revised 4 January 2011; Accepted 17 February 2011

Academic Editor: Iris Reuter

Copyright ( 92011 K. L. Best and W. C. Miller. This is an open access article distributed under the Creative Commons Attribution License, which permits unrestricted use, distribution, and reproduction in any medium, provided the original work is properly cited.

\begin{abstract}
Background. Physical and leisure activities are proven health promotion modalities and have not been examined in older wheelchair users. Main Objectives. Examine physical and leisure activity in older wheelchair users and explore associations between wheelchair use and participation in physical and leisure activity, and wheelchair use, physical and leisure activity, and perceived health. Methods. 8301 Canadians $\geq 60$ years of age were selected from the Canadian Community Health Survey. Sociodemographic, health-related, mobility-related, and physical and leisure activity variables were analysed using logistic regression to determine, the likelihood of participation in physical and leisure activity, and whether participation in physical and leisure activities mediates the relationship between wheelchair use and perceived health. Results. $8.3 \%$ and $41.3 \%$ older wheelchair users were physically and leisurely active. Wheelchair use was a risk factor for reduced participation in physical $(\mathrm{OR}=44.71)$ and leisure activity $(\mathrm{OR}=10.83)$. Wheelchair use was a risk factor for poor perceived health $(\mathrm{OR}=10.56)$ and physical and leisure activity negatively mediated the relationship between wheelchair user and perceived health. Conclusion. There is a need for the development of suitable physical and leisure activity interventions for older wheelchair users. Participation in such interventions may have associations with health benefits.
\end{abstract}

\section{Introduction}

Canadians aged 65 and older are 4 times more likely to use a wheelchair compared to those who are younger [1]. Previous estimates suggest that approximately $4.6 \%$ of adults aged 65 and older in the community [2] use a wheelchair for mobility. With predicted population estimates suggesting a two-fold increase in the number of adults aged 65 and older by 2020 [3], a substantial increase in the number of older wheelchair users is expected.

Both aging and wheelchair use are associated with deteriorations in physical functioning, which can lead to physiological deconditioning that is associated with numerous health risks, morbidity, and early mortality [4]. Lack of physical activity seemingly exacerbates physiological deconditioning, which can result in further accumulation of functional limitations and disability over time [5]. In fact, physical inactivity has been named the greatest health risk factor for older adults by the World Health Organization [6] and the 4th highest attributable risk of death in the USA [7]. It has been suggested that interventions which promote or maintain physical activity behavior among older adults with disabilities might provide an effective strategy for lessening the health risks of functional decline [8].

Physical activity, defined as bodily movements produced by skeletal muscles that result in energy expenditure [6], is a proven modality of health promotion. Physical activity interventions may optimize physical functioning and slow the spiralling effects of deconditioning in adults with chronic conditions [9] and disabilities [10]. The benefits of physical activity include associations with decreased morbidity and early mortality risk for older adults [7], improved stamina and muscle strength in individuals with chronic and disabling conditions, reduced anxiety and depression, and improved mood and general feelings of well-being [11]. Similarly, physically active adults with mobility impairments 
are healthier than their less active peers and have decreased mortality risk [12] and younger physically active wheelchair users have improved functioning and less risk of early mortality risk compared to their inactive peers $[10,12]$.

General improvements in health and well-being for older individuals with a disability are also highly associated with participation in leisure activities. In fact, participation in leisure activities, defined as a nonobligatory activity that a person is engaged in during discretionary time [13], has been shown to be the primary predictor of well-being after stroke [14]. Participation in active leisure pursuits, which may include long walks, attending entertainment venues, and gardening, may also fit the definition of physical activity. Therefore, participation in active leisure pursuits may provide health benefits similar to those of participation in physical activity.

Previous findings have suggested that most of the association between physical impairment and lower well-being are explained by disability [14]. Adults with chronic conditions [15], older adults with arthritis [16] who participate in physical activity, and older adults after stroke who participate in leisure activity [17], report having better perceived health than those who do not participate in physical or leisure activity. Furthermore, participation in both physical and leisure activities has been shown to improve general well-being for individuals with disabilities $[11,18]$. Due to the associations of perceived health with objective health measures [19], health care costs, and mortality [20], improved perceived health due to increased physical activity is arguably just as important as the physical benefits [21].

The benefits of participation in physical and other leisure activities would be similar for older adult wheelchair users, but the likelihood of participation for people with disabilities is low $[14,22]$. The lack of participation may be a result of the numerous unique barriers faced by wheelchair users and the limited number of interventions that specifically address their complex needs. Physical activity participation levels among individuals with disabilities are affected by a complex set of barriers and facilitators that are unique to this population. These barriers and facilitators include the environment, emotional and psychological barriers, equipment barriers, information-related barriers, professional knowledge and training issues, attitudinal barriers, and availability of resources $[23,24]$. Since older wheelchair users are a heterogeneous group, with varying disabilities, functional limitations, and a diverse range of likes and dislikes, current physical activity models provide few choices given the environmental barriers that wheelchair users face. Finding suitable durations, frequencies and types of physical activity for wheelchair users also poses a complex challenge due to the variations in ability and in ways of moving [25]. Strategies that incorporate methods for enhancing selfefficacy along with the promotion of physical and other leisure activities have been suggested as a means of improving quality of life among older adults who have a disability $[8,17]$.

The association between wheelchair use and participation in physical activity and other leisure activities has not been documented to date. A better understanding of the prevalence of physical activity in older community-dwelling wheelchair users and its association with perceived health may provide insight and rationale for the development of appropriate physical and leisure activity interventions, which forms the purpose of this study.

The primary objectives of this study were to (1) examine participation in physical and leisure activity in older wheelchair users and (2) determine if there is an association between wheelchair use and participation in physical and leisure activity. The secondary objectives were to (1) examine perceived health in older wheelchair users and (2) determine if participation in physical and leisure activity mediates the relationship between wheelchair use and perceived health. The primary hypotheses were (1) wheelchair users would report lower levels of participation in physical and leisure activity compared to older adults who do not use a wheelchair and (2) wheelchair use would be a significant risk factor for reduced participation in physical and leisure activity. The secondary hypotheses were (1) older wheelchair users would have lower perceived health than older adults who do not use a wheelchair and (2) participation in physical and leisure activity would negatively mediate the relationship between wheelchair use and perceived health in older wheelchair users.

\section{Methods}

2.1. Design, Data Collection, and Subjects. Findings from this study were based on data collected for Canadian Community Health Survey (CCHS) Cycle 3.1, which were collected by Statistics Canada between January and December 2005. The CCHS cycle 3.1 was the third cross-sectional survey in a series of larger national surveys designed to estimate health determinants, health status, and health system utilization of Canadians. Subsample 1 of CCHS 3.1 was chosen as it was specifically designed to provide additional estimates for the Health Utility Index, which included questions related to functioning and mobility, including wheelchair use. Details of the CCHS, including a methodological overview have been previously published [26].

The target population of the CCHS was Canadians aged 12 and over. Individuals living on Indian Reserves and on Crown Lands, institutional residents, including nursing homes and long-term care facilities, full-time members of the Canadian Forces, and residents of certain remote regions were excluded from the sampling frame. A total of 32,153 Canadians were surveyed. For the purposes of this study, responses from all adults aged 60 and older $(n=8301)$ were included in the analyses. This subgroup was further divided into three categories: wheelchair users, nonwheelchair users who required some form of assistance to walk, and nonwheelchair users who did not require any assistance to walk. The data were collected by Statistics Canada under the authority of the Statistics Canada Act. Access to the data was granted by Statistics Canada based on a peer-reviewed proposal for the study. While the research and analysis are based on data from Statistics Canada, the opinions expressed do not represent the views of Statistics Canada. 
TABle 1: The questions used to calculate the Physical Activity Index. Respondents were asked: "Have you participated in the following physical activities for at least 15 minutes during the past 3 months".

\begin{tabular}{lc}
\hline Physical activity & \\
\hline Walking & Bowling \\
Gardening/yard work & Baseball or softball \\
Swimming & Tennis \\
Bicycling & Weight training \\
Popular/social dance & Fishing \\
Home exercises & Volleyball \\
Ice hockey & Basketball \\
Ice skating & Soccer \\
In-line skating/roll & Other $(\# 1)$ \\
Jogging or running & No physical activity \\
Golfing & Other $(\# 2)$ \\
Exercise class/aerobics & Other $(\# 3)$ \\
Skiing/snowboarding & \\
\hline
\end{tabular}

2.2. Classification of Wheelchair Use. Wheelchair use was identified using the Health Utility Index module of the CCHS. Respondents were initially asked, "Do you walk without difficulty or without support". Responses were coded dichotomously as "yes/no". If their answer was "no" or "unsure", respondents were asked, "Do you walk with assistance from another person" and "Do you walk with assistance using an assistive device". For the purposes of this study, responses from these two questions were collapsed into one variable, "walk with assistance", which was coded dichotomously as "yes/no". In addition, those who responded they required assistance to walk were also asked, "Do you require a wheelchair for mobility". If the respondent used a wheelchair, and could walk with assistance, they were classified as a wheelchair user in this study, and the responses were coded dichotomously as "yes/no". Two subgroups of older adults who did not use a wheelchair were identified (walk without difficulty or without support, and walk with assistance) for comparisons with older wheelchair users, and both were coded dichotomously as "yes/no".

2.3. Dependent Variables. Participation in physical and leisure activities were assessed using two questions from the Physical Activity module of the CCHS. The Physical Activity Index provided an indication of the amount of participation in physical activity through estimates of overall energy expenditure from physical activity. This was calculated using the type of physical activity, and frequency and duration of each physical activity session, as well as the MET (metabolic equivalent) values for each physical activity. Respondents were asked which physical activities they participated in for at least 15 minutes during the past 3 months from a preset list determined by Statistics Canada, which included activities such as going for a walk, gardening, and/or lifting weights. If the list did not include a specific activity, the respondent was given the option to respond "other". The "other" option was able to be selected up to three times by the respondent, thus capturing physical activities that were not necessarily included on the list. The response option, "did not take part in any physical activity for at least 15 minutes during the past 3 months" was also available to respondents. A complete list of the questions used to calculate the Physical Activity Index is shown in Table 1.

The MET is the energy cost of the activity expressed as kilocalories expended per kilogram of body weight per hour of activity, doing a physical activity during the past 3 months, the number of times, and time spent on each activity. The derived Physical Activity Index [27] resulted in three categories, including "Active", "Moderately Active", and "Inactive". "Active" corresponded to an average of $3.0+\mathrm{kcal} / \mathrm{kg} /$ day of energy expenditure, or the amount of exercise required for cardiovascular health benefits. "Moderately Active" corresponded to energy expenditure of 1.5$2.9 \mathrm{kcal} / \mathrm{kg} / \mathrm{day}$, or some health benefits but little cardiovascular benefit. "Inactive" corresponded to energy expenditure below $1.5 \mathrm{kcal} / \mathrm{kg} /$ day or little to no health benefits. Although the Physical Activity Index included 3 questions which asked the respondents whether they participated in "other" physical activities during the past 3 months, it is not clear how the METs were calculated for these variables. For the purposes of this study, the three categories were recoded into dichotomous outcomes as "active (active/moderately active)/inactive". All nonresponses for this variable were coded as "inactive".

Participation in leisure activity was measured using one question on the CCHS, which asked whether or not respondents participated in leisure activities during the last 3 months. The responses were coded dichotomously as "yes/no". Leisure activities included playing cards or other games, listening to radio or music, doing crafts or other hobbies, visiting with family and friends, and attending events or entertainment. Leisure activities did not include reading a book or watching television.

Perceived health was assessed using the self-rated health variable, which is indicative of the respondent's health status at that point in time based on personal judgment. Selfrated health was assessed using a 5-point ordinal scale (poor, fair, good, very good, excellent), and responses were recoded as dichotomous outcomes for "poor-fair/good-excellent" for the purposes of study.

2.4. Independent Variables. Sociodemographic (age, sex, marital status, education, income) and health-related (body mass index (BMI), tobacco use, alcohol consumption, having a chronic condition) covariates were included for analyses. Age was collected as a continuous variable and sex was coded dichotomously as "male/female". Marital status was included in this report as a proxy measure of social support. It was originally coded using a 5-point ordinal scale (married, common law, widowed, divorced, single), but for analyses purposes it was collapsed into dichotomous variable ("marriedcommon law/widowed-divorced-single”). Education level was reflective of whether or not the respondent graduated from high school or not. Household income was originally collected as a continuous variable, but was collapsed and coded dichotomously as "CAD < 14999/CAD > 15000". 
Self-reports of height and weight were used to calculate $\mathrm{BMI}$ as a continuous variable. Respondents were asked to indicate their current tobacco use on a 3-point ordinal scale (daily, occasional, never), which was recoded dichotomously as "daily-occasional/never". Alcohol use was originally coded using a 4-point ordinal scale (regular, occasional, former, never), which was recoded dichotomously as "regularoccasional/former-never". The existence of one or more chronic conditions was assessed by whether respondents had been diagnosed by a healthcare professional as having a disease or other health condition that had lasted for, or was expected to last for, 6 months or longer. Responses were coded dichotomously as "yes/no".

2.5. Statistical Analysis. The raw data were obtained from the Statistics Canada Research Data Centre, University of British Columbia, Vancouver, British Columbia. As suggested by Statistics Canada, bootstrapping methods were used to apply sampling weights to estimate the variance of all point estimates based on 500 replications for each model in order to correct for unequal probabilities of selection in calculating variances.

The sample groups were described using summary statistics based on their group status.

\section{Primary Objectives}

Prevalence of wheelchair use in adults aged sixty and older was calculated using frequency counts.

Participation in physical and leisure activity (Physical Activity Index, participation in leisure activity) was compared between older adults who do and do not use a wheelchair using percent concordances.

Wheelchair use as a risk factor for decreased participation in physical activity was assessed using multivariate logistic regression, while controlling for sociodemographic and health-related variables. Odds ratios (OR) and 95\% confidence intervals (CI) were estimated for each variable to determine the differences in participation in physical and leisure activities between each group (older wheelchair users, older adults who could walk with support) and to examine the association between wheelchair use and participation in physical and leisure activities.

\section{Secondary Objectives}

The perceived health of older wheelchair users was compared to the perceived health of older adults who do not use a wheelchair using percent concordances.

The association between participation in physical and leisure activity and poorer perceived health in older wheelchair users was estimated using 2 multivariate logistic regression models. The initial model produced ORs and 95\% CIs for each variable to estimate risk factors of poor perceived health in wheelchair users. Physical and leisure activity were then added to the model 250 to examine if participation in physical and leisure activity mediated the relationship between 251 wheelchair use and perceived health. All data were analyzed using SPSS (Version 13.0, Chicago, IL, USA) software.

\section{Results}

Weighted estimates suggested that the population of community-based Canadians aged 60 and older was approximately 5,362,000 and the estimated prevalence of wheelchair use within this population was approximately 100,000. The average (SD) age of the subsample of wheelchair users was 76.4 (9.5) years, of which $62 \%$ were female. The estimated proportions for the sociodemographic and health-related variables are described in Table 2.

3.1. Physical and Leisure Activity. Approximately $8.3 \%$ of community-based wheelchair users aged 60 and older reported being physically active, compared to $16.5 \%$ and $48.8 \%$ of older adults who walked with and without assistance, respectively. Participation in leisure activity was higher in all groups, with approximately $41.3 \%$ of communitybased wheelchair users compared to $64.6 \%$ and $88.9 \%$ of older adults who walked with and without assistance, respectively, reporting they took part in leisure activities (Table 2).

\subsection{Predictors of Participation in Physical and Leisure Activity.} After controlling for sociodemographic (age, sex, marital status, income) and health related (BMI, tobacco use, alcohol consumption) variables, multivariate logistic regression showed that older adults who walked with assistance (Odds Ratio $(\mathrm{OR})=2.96,95 \%$ CI 2.16, 4.04) were less likely than older adults who walked without assistance to participate in physical activity. Likewise, wheelchair users were even less likely to participate in physical activity compared to older adults who could walk $(\mathrm{OR}=44.71,95 \%$ CI 0.02 , $\left.3.31 \mathrm{e}^{6}\right)$.

Tobacco use and higher BMI were significant risk factors for reduced physical activity, while increasing age was a slight risk factor for reduced participation in physical activity. Predictors of being physically active included being male, graduating from high school, and consuming any alcohol. Marital status, income, and having a chronic condition were not significant risk factors for reduced participation in physical activity. See Table 3 for detailed information of this model.

Both older wheelchair users $(\mathrm{OR}=10.83,95 \% \mathrm{CI}$ $5.84,20.05)$ and older adults who walked with assistance $(\mathrm{OR}=4.24,95 \%$ CI 3.08, 5.84) were less likely than older adults who could walk without assistance to participate in leisure activity, after controlling for sociodemographic and health-related variables. Tobacco use was a significant risk factor for reduced participation in leisure activity, while alcohol consumption had a protective association. Age, sex, marital status, education, income category, BMI, and having a chronic condition were not significant predictors of participation in leisure activities.

See Table 3 for detailed information of this model. 
TABle 2: Description of Canadian Community Health Survey 3.1 subsample 1 respondents aged 60 and over.

\begin{tabular}{|c|c|c|c|}
\hline Population estimates & $\begin{array}{l}\text { Walk }(n=7217) \\
\qquad \begin{array}{c}4738248 \\
(88.4 \%)\end{array}\end{array}$ & $\begin{array}{l}\text { Walk with assistance }(n=935) \\
\qquad \begin{array}{l}523577 \\
(11.3 \%)\end{array}\end{array}$ & $\begin{array}{l}\text { Wheelchair user }(n=149) \\
\qquad 99992 \\
(1.9 \%)\end{array}$ \\
\hline \multicolumn{4}{|l|}{ Sociodemographic variables } \\
\hline Age mean $(\mathrm{SD})$, range & $69.6(7.4), 60-100$ & $76.8(8.7), 60-98$ & $76.4(9.5), 60-93$ \\
\hline \multicolumn{4}{|l|}{$\operatorname{Sex}(\%)$} \\
\hline Male & 47.4 & 34.9 & 38 \\
\hline Female & 52.6 & 65.1 & 62 \\
\hline \multicolumn{4}{|l|}{ Marital status (\%) } \\
\hline Married/common law & 68.5 & 45.6 & 49.2 \\
\hline Single/widowed/divorced & 31.5 & 54.4 & 50.8 \\
\hline \multicolumn{4}{|l|}{ Graduated high school (\%) } \\
\hline Yes & 51.7 & 38.3 & 46.7 \\
\hline No & 48.3 & 61.2 & 53.3 \\
\hline \multicolumn{4}{|l|}{ Income $(\%)$} \\
\hline CAD $<14999$ & 8.3 & 85 & 81.4 \\
\hline $\mathrm{CAD}>15000$ & 91.7 & 15 & 18.6 \\
\hline \multicolumn{4}{|l|}{ Health-related variables } \\
\hline $\mathrm{BMI}^{\dagger}\left(\mathrm{m} / \mathrm{Kg}^{2}\right)$, mean $(\mathrm{SD})$ & $26.1(4.3)$ & $27.4(5.9)$ & $26.6(5.9)$ \\
\hline \multicolumn{4}{|l|}{ Smoker type (\%) } \\
\hline Daily/occasionally & 12.6 & 12.6 & 15.1 \\
\hline Never & 87.3 & 87.4 & 84.9 \\
\hline \multicolumn{4}{|l|}{ Alcohol consumption (\%) } \\
\hline Regular/occasional & 72.8 & 56.4 & 57.4 \\
\hline Former/never & 27.2 & 43.6 & 42.6 \\
\hline \multicolumn{4}{|l|}{ Has a chronic condition (\%) } \\
\hline Yes & 88 & 97.9 & 100 \\
\hline No & 12 & 2.1 & - \\
\hline \multicolumn{4}{|l|}{ Dependent variables } \\
\hline \multicolumn{4}{|l|}{ Physical activity index (\%) } \\
\hline Active/moderately active & 48.4 & 16.5 & 8.3 \\
\hline Inactive & 51.6 & 83.5 & 91.7 \\
\hline \multicolumn{4}{|l|}{ Participate leisure activity (\%) } \\
\hline Yes & 88.9 & 64.6 & 41.3 \\
\hline No & 11.1 & 35.4 & 58.7 \\
\hline \multicolumn{4}{|l|}{ Self rated health $(\%)$} \\
\hline Poor/fair & 18.1 & 56.8 & 74.2 \\
\hline Good/very Good/excellent & 81.9 & 43.2 & 25.8 \\
\hline
\end{tabular}

Note: results are weighted to provide proportional representation of the Canadian population.

${ }^{\dagger}$ Body mass index.

3.3. Risks Factors for Poor Perceived Health. Approximately $74.2 \%$ of community-based wheelchair users aged 60 and older reported having poor perceived health, compared to $56.8 \%$ and $18.1 \%$ of older adults who walked with and without assistance, respectively (Table 2).

Multivariate logistic regression suggested that using a wheelchair $(\mathrm{OR}=10.56,95 \%$ CI 5.90, 18.92, $P<.001)$ and requiring assistance to walk $(\mathrm{OR}=4.18,95 \% \mathrm{CI}$ $3.05,5.75, P<.001)$ were significant risk factors for poor perceived health compared to older adults who walked without assistance. Having a chronic condition, smoking, and having an income of less than 14,999 CAD were also significant risk factors for poor perceived health, while graduating from high school and consuming alcohol had a protective effect. Age, sex, and BMI were not significant predictors of poor perceived health in older adults.

See Table 4 for detailed information of this model.

When participation in physical and leisure activity was added to the model, logistic regression analyses showed that both reduced participation in physical activity $(\mathrm{OR}=1.64$, 
TABle 3: Association of wheelchair use, sociodemographic and health-related variables on physical and leisure activity in older Canadian adults.

\begin{tabular}{|c|c|c|c|c|c|c|}
\hline \multirow{2}{*}{ Sociodemographic variables } & \multicolumn{3}{|c|}{ Physical activity index } & \multicolumn{3}{|c|}{ Participates in leisure activities } \\
\hline & OR & $95 \% \mathrm{CI}$ & $P$ & OR & $95 \% \mathrm{CI}$ & $P$ \\
\hline Age (years) & 1.03 & $1.02,1.05$ & $<.001$ & 1.02 & $1.00,1.04$ & .02 \\
\hline \multicolumn{7}{|l|}{ Sex } \\
\hline Male & 0.72 & $0.61,0.84$ & $<.001$ & 1.16 & $0.93,1.44$ & .18 \\
\hline \multicolumn{7}{|l|}{ Marital status } \\
\hline Married/common law & 0.98 & $0.83,1.16$ & .83 & 1.08 & $0.86,1.36$ & .52 \\
\hline \multicolumn{7}{|l|}{ Education } \\
\hline Graduated from high school & 0.62 & $0.52,0.73$ & $<.001$ & 0.61 & $0.49,0.76$ & $<.001$ \\
\hline \multicolumn{7}{|l|}{ Income } \\
\hline CAD $<14999$ & 1.05 & $0.81,1.34$ & .74 & 1.14 & $0.86,1.51$ & .37 \\
\hline \multicolumn{7}{|l|}{ Health related variables } \\
\hline $\mathrm{BMI}\left(\mathrm{m} / \mathrm{Kg}^{2}\right)$ & 1.07 & $1.05,1.09$ & $<.001$ & 1.04 & $1.01,1.06$ & $<.001$ \\
\hline \multicolumn{7}{|l|}{ Type of smoker } \\
\hline Regular/occasional & 1.95 & $1.51,2.52$ & $<.001$ & 1.81 & $1.33,2.46$ & $<.001$ \\
\hline \multicolumn{7}{|l|}{ Alcohol use } \\
\hline Regular/occasional & 0.74 & $0.61,0.89$ & $<.001$ & 0.54 & $0.43,0.69$ & $<.001$ \\
\hline \multicolumn{7}{|l|}{ Has a chronic condition } \\
\hline Yes & 1.12 & $0.086,1.46$ & .41 & 7.60 & $3.20,18.03$ & $<.001$ \\
\hline \multicolumn{7}{|l|}{ Wheelchair use } \\
\hline No (walks with support) & 2.96 & $2.16,4.04$ & $<.001$ & 4.24 & $3.08,5.84$ & $<.001$ \\
\hline Yes & 44.71 & $0.002,3.3 \mathrm{e}^{6}$ & .51 & 10.83 & $5.84,20.05$ & $<.001$ \\
\hline
\end{tabular}

$95 \%$ CI 1.29, 2.07) and leisure activity (OR = 1.67, $95 \%$ CI $1.24,2.26$ ) were significant risk factors for poor perceived health. Adding participation in physical and leisure activity to the model reduced the Odds Ratio for both older wheelchair users $(\mathrm{OR}=6.94,95 \% \mathrm{CI} 3.81,12.65, P<.001)$ and older adults who could walk with assistance $(\mathrm{OR}=3.63$, 95\% CI 2.64, 4.99, $P<.001)$. The other sociodemographic and health-related variables were not influenced by the addition of participation in physical and leisure activity to the model (Table 4).

\section{Discussion}

The prevalence of wheelchair use in adults aged 60 and older adults living in the community was estimated to be approximately 100,000. Although this estimate corresponded with previous estimates of wheelchair users aged 65 and older by Shields [1] $(n=81300)$ and Clark and Colantonio [2] ( $n=88300)$, it is thought to be an underrepresentation of the actual number of Canadian wheelchair users aged 60 and older. Despite efforts to account for unequal sampling probabilities, the small CCHS subsample only includes community living individuals and not those who live in Indian reserves or in institutions.

The overall purpose of this paper was to examine participation in physical and leisure activities in older wheelchair users and to examine the association of wheelchair use and physical and leisure activity on perceived health. As hypothesized, wheelchair users were significantly less likely to participate in leisure activities compared to those who walked with or without support and wheelchair use seemingly increased the likelihood for reduced participation in physical activity. Wheelchair use was also a significant risk factor for poor perceived health, and participation in physical and leisure activity were shown to have a negative mediating effect on the associations between wheelchair use and perceived health.

Although recent findings suggest the number of physically active older adults is slowly increasing [28], there is still a large portion of the population who are not active enough to receive health benefits [9]. Findings from this study suggest this is particularly true for older adults who use wheelchairs, as only $8.3 \%$ of wheelchair users reported participating in physical activity compared to $48.8 \%$ of older adults who walked without support. Due to the collapsing of the "moderately active" and "active" variables within the Physical Activity Index, being physically active within this sample represented an energy expenditure of 1.5 to greater than $3 \mathrm{kcal} / \mathrm{kg} /$ day. Therefore, the percentage of individuals who meet the recommended $1000 \mathrm{kcal} / \mathrm{kg} /$ day [29] is likely much smaller than the reported findings in this study values with respect to prevalence of physical activity.

A larger proportion of the population reported participating in leisure activity. Since some of the leisure activities reported may be active leisure pursuits, it is likely that a portion of the $41.3 \%$ of older wheelchair users who reported taking part in leisure activities would be participating in 
TABLE 4: A Summary of risk factors for predictive models of perceived health in older Canadian adults.

\begin{tabular}{|c|c|c|c|c|c|c|}
\hline \multirow{2}{*}{ Sociodemographic variables } & \multicolumn{3}{|c|}{ Perceived health (model 1) } & \multicolumn{3}{|c|}{ Perceived health (model 2) } \\
\hline & OR & $95 \% \mathrm{CI}$ & $P$ & OR & $95 \%$ CI & $P$ \\
\hline Age (years) & 1.02 & $1.01,1.04$ & $<.001$ & 1.02 & $1.00,1.03$ & .05 \\
\hline \multicolumn{7}{|l|}{ Sex } \\
\hline Male & 1.15 & $0.92,1.43$ & .21 & 1.20 & $0.96,1.50$ & .11 \\
\hline \multicolumn{7}{|l|}{ Marital status } \\
\hline Married/common law & 1.0 & $0.80,1.25$ & .98 & 1.00 & $0.80,1.25$ & .35 \\
\hline \multicolumn{7}{|l|}{ Education } \\
\hline Graduated from high school & 0.56 & $0.46,0.70$ & $<.001$ & 0.61 & $0.49,0.76$ & $<.001$ \\
\hline \multicolumn{7}{|l|}{ Income } \\
\hline CAD $<14999$ & 1.13 & $0.85,1.50$ & .40 & 1.14 & $0.86,1.51$ & .37 \\
\hline \multicolumn{7}{|l|}{ Health related variables } \\
\hline $\mathrm{BMI}\left(\mathrm{m} / \mathrm{Kg}^{2}\right)$ & 1.04 & $1.01,1.06$ & $<.001$ & 1.03 & $1.00,1.05$ & .04 \\
\hline \multicolumn{7}{|l|}{ Type of smoker } \\
\hline Regular/occasional & 1.89 & $1.38,2.59$ & $<.001$ & 1.72 & $1.26,2.36$ & $<.001$ \\
\hline \multicolumn{7}{|l|}{ Alcohol use } \\
\hline Regular/occasional & 0.52 & $0.41,0.66$ & $<.001$ & 0.55 & $0.43,0.70$ & $<.001$ \\
\hline \multicolumn{7}{|l|}{ Has a chronic condition } \\
\hline Yes & 7.60 & $3.21,18.07$ & $<.001$ & 7.48 & $3.18,17.57$ & $<.001$ \\
\hline \multicolumn{7}{|l|}{ Wheelchair use } \\
\hline No (walks with support) & 4.18 & $3.05,5.75$ & $<.001$ & 3.63 & $2.64,4.99$ & $<.001$ \\
\hline Yes & 10.56 & $5.90,18.92$ & $<.001$ & 6.94 & $3.81,12.65$ & $<.001$ \\
\hline \multicolumn{7}{|l|}{ Physical Activity Index } \\
\hline Inactive & - & & & 1.64 & $1.29,2.07$ & $<.001$ \\
\hline \multicolumn{7}{|l|}{ Participates in leisure activities } \\
\hline No & - & & & 1.67 & $1.24,2.26$ & $<.001$ \\
\hline
\end{tabular}

Model 1: impact of wheelchair use on perceived health, controlled for sociodemographic and health-related variables.

Model 2: impact of wheelchair use on perceived health after adding physical activity behaviours to the model, controlled for sociodemographic and healthrelated variables.

more physical activity than if they were not participating in those leisure activities. It is possible that physical activity levels in older wheelchair users may have been underestimated by the Physical Activity Index alone. However, findings from a recent study suggest that individuals with disabilities are limited to more passive leisure activities, due to limited mobility, loss of function, and fatigue [17]. Regardless, it is clear that wheelchair users take part in less leisure activity compared to $64.6 \%$ of older adults who walk with support and $88.9 \%$ of adults who walk without support. This is an important finding as participation in leisure activities has been shown to have similar health benefits as participation in physical activity for older adults, including contributions to successful aging by reducing the risk of premature death [30], and improving overall function [31].

Logistic regression analyses suggest that wheelchair use may be a risk factor for reduced participation in physical activity $(\mathrm{OR}=44.71)$ and is a significant risk factor for reduced participation in leisure activity $(\mathrm{OR}=2.96)$. Although the odds ratios suggest that wheelchair use increased the likelihood of not participating in physical activity, the extremely large variance of these estimates suggests these findings must be interpreted with caution.
Despite the large variance in this point estimate for the Physical Activity Index, it is clear that a large portion of older wheelchair users are not physically active and are not receiving the benefits of physical activity. The other protective factors in the logistic model for physical activity and leisure activity are supported by previous findings of older adults [9], which showed that males who graduated from high school and consumed alcohol were more likely to take part in physical activity behaviour.

Wheelchair use $(\mathrm{OR}=10.56)$ was also found to be a significant risk factor for poor perceived health compared to those who did not use wheelchair. Similar to previous findings, having a chronic condition [7, 32], smoking [33], and having a higher BMI were also significant risk factors for poor perceived health, while graduating from high school and consuming alcohol [9] had a protective effect on perceived health.

Reduced participation in physical activity $(\mathrm{OR}=1.64)$ and leisure activity $(\mathrm{OR}=1.67)$ was also a significant risk factor for poor perceived health. Moreover, when physical activity behaviours were added to the model, using a wheelchair $(\mathrm{OR}=6.99)$ was reduced somewhat, but was still a significant factor in predicting poor perceived health. 
These findings suggest that regardless of sociodemographic and health-related variables, participation in physical activity behaviours can significantly reduce the risk of having poor perceived health in older wheelchair users. This is supported by previous findings which showed that participation in leisure time physical activity had a graded and continuous association with better self-rated health in older adults [34]. Furthermore, this study also suggested that even small amounts of leisure-time physical activity are related to a better health status, which can be summarized and linked to the clinical and public health recommendations that "even a little is good; more is better" [35].

The health benefits of physical $[6,7,10,36]$ and leisure activity $[14,17,18,24]$ are well documented. Findings from this study suggest that participating in physical and leisure activity is associated with improved perceived health, which may also be associated with improved quality of life for older wheelchair users. Furthermore, ratings of perceived health have been shown to be highly predictive of mortality [32]. While the benefits of exercise are well known, it is likely that wheelchair users who are quite sedentary may benefit from small increases in physical and leisure activities that require more bodily movement than what is normally done. The findings from this study highlight the need for targeted surveys of older wheelchair users that incorporate appropriate, accessible, and desired physical and leisure activities, and indentify the need for the development of interventions that include a broad range of physical and leisure activities.

The cross-sectional nature of this study imposed inconclusive findings regarding the causality and direction of the relationships of the variables studied. It can only be concluded that there are associations between wheelchair use and participation in physical and leisure activity and between participation in physical and leisure activity and poorer perceived health.

Also, the pre-defined structure of the questions imposed some uncontrollable limitations to the findings of this study. The study variables (i.e., physical and leisure activity) were challenging to define due to the structure of the questions on the CCHS. The broad questions asked about physical and leisure activity left some uncertainty about the activities the respondents participated in. Due to the challenges with defining physical and leisure activity, the results must be interpreted with caution. The types of physical activities asked of the respondents and the uncertainty of the methods used for calculating energy expenditure for the "other" categories of the Physical Activity Index may not have provided an ideal assessment of participation in physical activities for older wheelchair user, which may include wheeling or other physical activities that can be done in a wheelchair. The inclusion of participation in leisure activities in the models must also be interpreted with caution, as there is uncertainty as to which specific leisure activities the respondents took part in. However, since some leisure activities fit the definition of physical activity, and because there are some similar health benefits of both physical and leisure activity, it was felt that examining the associations between wheelchair use and participation in leisure activity was important for gaining a comprehensive understanding of participatory behaviours of older wheelchair users. It should also be noted that activities of daily living and occupational activities, both of which may include activities that fit our definition of physical activity, were not included in our analyses. Therefore, it is likely that our findings underrepresent the amount of physical activity that older wheelchair users take part in. Despite the exclusion of activities of daily living and occupational activities, our findings do suggest that very few older adult wheelchair users participate in enough physical and leisure activities to receive health benefits.

\section{Significance}

Findings from this study suggest that older wheelchair users are not as physically or leisurely active as those who do not use a wheelchair; current physical activity measurement tools are not appropriate for older wheelchair users; there is a need for the development of accessible physical and leisure activity interventions. Interventions that focus on promoting physical and leisure activities may lead to increased participation in physical and leisure activity, which is associated with improvements in perceived health for older wheelchair users. Appropriate interventions for this target population should focus on counselling for behaviour change and should include suitable and accessible activities that are appealing to older adult wheelchair users.

\section{Conclusion}

Wheelchair use is associated with reduced participation in physical and leisure activity, and both wheelchair use and reduced physical and leisure activity are significantly associated with poor perceived health. Perceived health is correlated to objective health measures, both of which may be improved through interventions that target health-related behaviours changes, such as participation in physical and leisure activity. Participation in such interventions may be associated with health benefits.

\section{References}

[1] M. Shields, "Use of wheelchairs and other mobility support devices," Health Reports, vol. 15, no. 3, pp. 37-41, 2004.

[2] P. Clarke and A. Colantonio, "Wheelchair use among community-dwelling older adults: prevalence and risk factors in a national sample," Canadian Journal on Aging, vol. 24, no. 2, pp. 191-198, 2005.

[3] R. Li, A. Iadarola, and C. Maisano, Why Population Aging Matters: A Global Perspective, National Institutes of Health, Department of State, Department of Health and Human Services, 2007.

[4] J. H. Rimmer, "Use of the ICF in identifying factors that impact participation in physical activity/rehabilitation among people with disabilities," Disability and Rehabilitation, vol. 28, no. 17, pp. 1087-1095, 2006.

[5] W. J. Rejeski, L. R. Brawley, and W. L. Haskell, "Physical activity: preventing physical disablement in older adults," 
American Journal of Preventive Medicine, vol. 25, no. 3, pp. 107-217, 2003.

[6] World Health Organization, 2009, http://www.who.int/.

[7] R. Sawatzky, T. Liu-Ambrose, W. C. Miller, and C. A. Marra, "Physical activity as a mediator of the impact of chronic conditions on quality of life in older adults," Health and Quality of Life Outcomes, vol. 5, article 68, 2007.

[8] R. W. Motl and E. McAuley, "Physical activity, disability, and quality of life in older adults," Physical Medicine and Rehabilitation Clinics of North America, vol. 21, no. 2, pp. 299308, 2010.

[9] M. C. Ashe, W. C. Miller, J. J. Eng, and L. Noreau, "Older adults, chronic disease and leisure-time physical activity," Gerontology, vol. 55, no. 1, pp. 64-72, 2009.

[10] J. L. Durstine, P. Painter, B. A. Franklin, D. Morgan, K. H. Pitetti, and S. O. Roberts, "Physical activity for the chronically Ill and disabled," Sports Medicine, vol. 30, no. 3, pp. 207-219, 2000.

[11] National Centre for Chronic Disease Prevention and Health Promotion, "Physical activity and health: a report of the Surgeon General (Persons with disabilities)," CDC, 1999, http: //www.cdc.gov/nccdphp/sgr/disab.htm.

[12] C. A. Warms, B. L. Belza, and J. D. Whitney, "Correlates of physical activity in adults with mobility limitations," Family and Community Health, vol. 30, no. 2, pp. S5-S16, 2007.

[13] S. S. Roley, J. V. DeLany, C. J. Barrows et al., "Occupational therapy practice framework: domain \&amp; process 2nd edition," American Journal of Occupational Therapy, vol. 62, no. 6, pp. 625-683, 2008.

[14] U. Sveen, B. Thommessen, E. Bautz-Holter, T. B. Wyller, and K. Laake, "Well-being and instrumental activities of daily living after stroke," Clinical Rehabilitation, vol. 18, no. 3, pp. 267-274, 2004.

[15] C. A. Cott, M. A. M. Gignac, and E. M. Badley, "Determinants of self rated health for Canadians with chronic disease and disability," Journal of Epidemiology and Community Health, vol. 53, no. 11, pp. 731-736, 1999.

[16] J. Freelove-Charton, H. R. Bowles, and S. Hooker, "Healthrelated quality of life by level of physical activity in arthritic older adults with and without activity limitations," Journal of Physical Activity \& Health, vol. 4, no. 4, pp. 481-494, 2007.

[17] C. O'Sullivan and G. Chard, "An exploration of participation in leisure activities post-stroke," Australian Occupational Therapy Journal, vol. 57, no. 3, pp. 159-166, 2010.

[18] V. Ball, S. Corr, J. Knight, and M. J. Lowis, "An investigation into the leisure occupations of older adults," British Journal of Occupational Therapy, vol. 70, no. 9, pp. 393-400, 2007.

[19] M. Pinquart, "Correlates of subjective health in older adults: a meta-analysis," Psychology and Aging, vol. 16, no. 3, pp. 414426, 2001.

[20] M. Jylhä, "What is self-rated health and why does it predict mortality? Towards a unified conceptual model," Social Science and Medicine, vol. 69, no. 3, pp. 307-316, 2009.

[21] R. A. Cooper, L. A. Quatrano, P. W. Axelson et al., "Research on physical activity and health among people with disabilities: a consensus statement," Journal of Rehabilitation Research and Development, vol. 36, no. 2, pp. 142-154, 1999.

[22] Canadian Fitness and Lifestyle Research Institute, "How active are Canadians? Progress in Prevention," http://www.cflri.ca/ pdf/e/pip01.pdf.
[23] H. Hoenig, L. R. Landerman, K. M. Shipp, and L. George, "Activity restriction among wheelchair users," Journal of the American Geriatrics Society, vol. 51, no. 9, pp. 1244-1251, 2003.

[24] E. A. Vanner, P. Block, C. C. Christodoulou, B. P. Horowitz, and L. B. Krupp, "Pilot study exploring quality of life and barriers to leisure-time physical activity in persons with moderate to severe multiple sclerosis," Disability and Health Journal, vol. 1, no. 1, pp. 58-65, 2008.

[25] C. A. Warms, J. D. Whitney, and B. Belza, "Measurement and description of physical activity in adult manual wheelchair users," Disability and Health Journal, vol. 1, no. 4, pp. 236-244, 2008.

[26] Y. Béland, "Canadian community health survey-methodological overview," Health Reports, vol. 13, no. 3, pp. 520-528, 2002.

[27] Statistics Canada, "Canadian Community Health Survey (CCHS 3.1)," 2005, http://www.statcan.gc.ca/concepts/healthsante/cycle3_1/index-eng.htm.

[28] J. C. Woolcott, M. C. Ashe, W. C. Miller, P. Shi, and C. A. Marra, "Does physical activity reduce seniors' need for healthcare?: a study of 24281 Canadians," British Journal of Sports Medicine, vol. 44, no. 12, pp. 902-904, 2010.

[29] US Department of Health and Human Services, Physical Activity and Health: A Report of the Surgeon General, Atlanta US Department of Health and Human Services, Centre for Disease Control and Prevention, National Centre for Chronic Disease Prevention and Health Promotion, 1996.

[30] A. Rodriguez-Laso, M. V. Zunzunegui, and A. Otero, "The effect of social relationships on survival in elderly residents of a Southern European community: a cohort study," BMC Geriatrics, vol. 7, article 19, 2007.

[31] A. Kono, I. Kai, C. Sakato, and L. Z. Rubenstein, "Frequency of going outdoors predicts long-range functional change among ambulatory frail elders living at home," Archives of Gerontology and Geriatrics, vol. 45, no. 3, pp. 233-242, 2007.

[32] D. Kaleta, K. Polariska, E. Dziankowska-Zaborszczyk, W. Hanke, and W. Drygas, "Factors influencing self-perception of health status," Central European Journal of Public Health, vol. 17, no. 3, pp. 122-127, 2009.

[33] L. M. Lewis and B. J. Riegel, "Determinants of perceived health in older adults with hypertension," Heart and Lung, vol. 39, no. 1, pp. 41-49, 2010.

[34] I. Galán, C. M. Meseguer, R. Herruzo, and F. RodríguezArtalejo, "Self-rated health according to amount, intensity and duration of leisure time physical activity," Preventive Medicine, vol. 51, no. 5, pp. 378-383, 2010.

[35] I. M. Lee, "Dose-response relation between physical activity and fitness: even a little is good; more is better," Journal of the American Medical Association, vol. 297, no. 19, pp. 2137-2139, 2007.

[36] D. M. Buchner, S. A. A. Beresford, E. B. Larson, A. Z. LaCroix, and E. H. Wagner, "Effects of physical activity on health status in older adults-II: intervention studies," Annual Review of Public Health, vol. 13, pp. 469-488, 1992. 


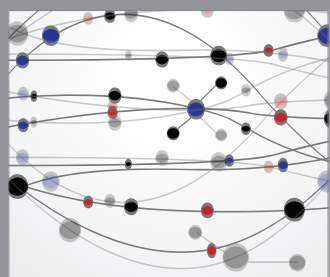

The Scientific World Journal
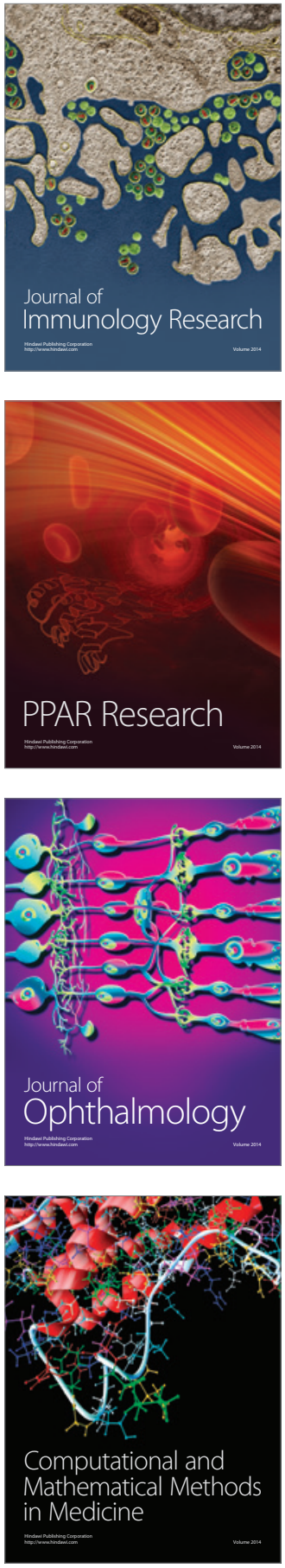

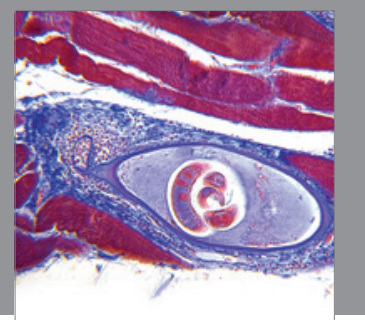

Gastroenterology

Research and Practice
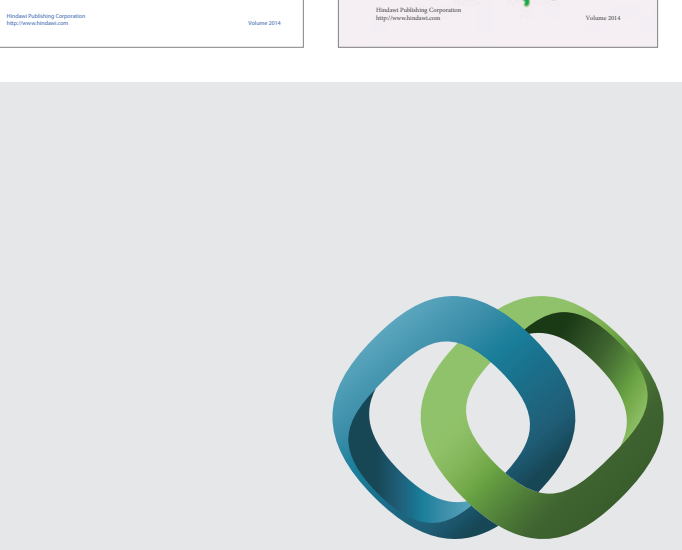

\section{Hindawi}

Submit your manuscripts at

http://www.hindawi.com
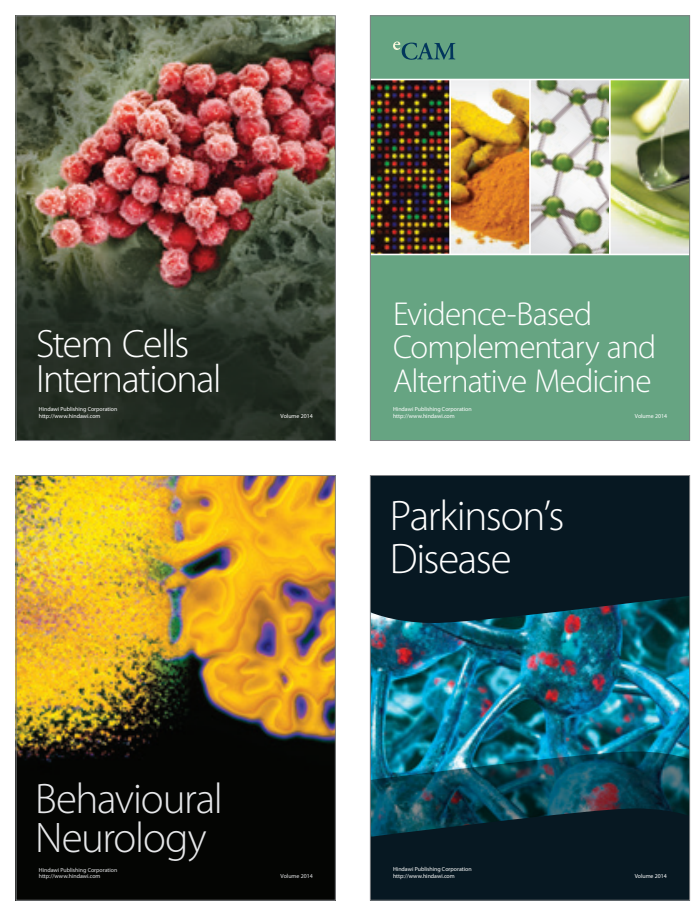

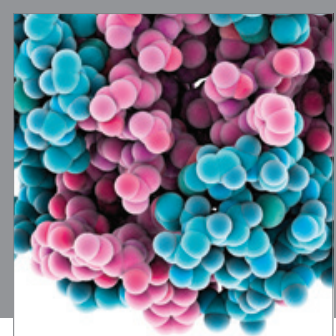

Journal of
Diabetes Research

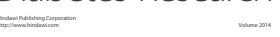

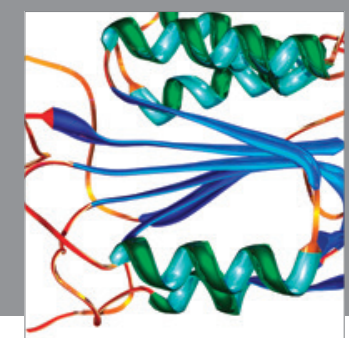

Disease Markers
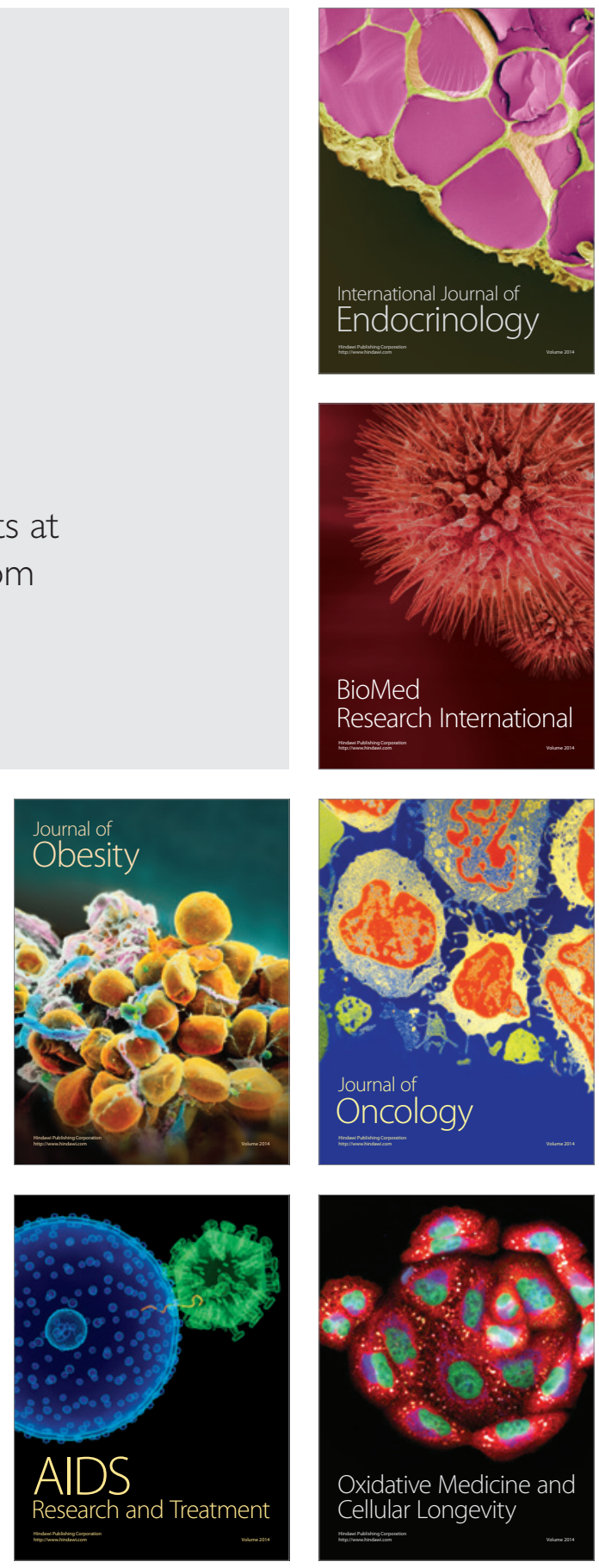